Research Paper

\title{
Improvement of submerged culture conditions to produce colorants by Penicillium purpurogenum
}

\author{
Valéria Carvalho Santos-Ebinuma ${ }^{1,4}$, Inês Conceição Roberto ${ }^{2}$, \\ Maria Francisca Simas Teixeira ${ }^{3}$, Adalberto Pessoa Jr. $^{1}$ \\ ${ }^{1}$ Departmento de Tecnologia Bioquímico-Farmacêutica, Universidade de São Paulo, \\ São Paulo, SP, Brazil \\ ${ }^{2}$ Departmento de Biotecnologia, Escola de Engenharia de Lorena, Universidade de São Paulo, Lorena, \\ SP, Brazil. \\ ${ }^{3}$ Coleção de Cultura DPUA/UFAM, Universidade Federal do Amazonas, Manaus, AM, Brazil. \\ ${ }^{4}$ Departamento de Bioprocessos e Biotecnologia, Faculdade de Ciências Farmacêuticas, Universidade \\ Estadual Paulista-UNESP, Araraquara, SP, Brazil.
}

Submitted: November 6, 2012; Approved: September 9, 2013.

\begin{abstract}
Safety issues related to the employment of synthetic colorants in different industrial segments have increased the interest in the production of colorants from natural sources, such as microorganisms. Improved cultivation technologies have allowed the use of microorganisms as an alternative source of natural colorants. The objective of this work was to evaluate the influence of some factors on natural colorants production by a recently isolated from Amazon Forest, Penicillium purpurogenum DPUA 1275 employing statistical tools. To this purpose the following variables: orbital stirring speed, $\mathrm{pH}$, temperature, sucrose and yeast extract concentrations and incubation time were studied through two fractional factorial, one full factorial and a central composite factorial designs. The regression analysis pointed out that sucrose and yeast extract concentrations were the variables that influenced more in colorants production. Under the best conditions (yeast extract concentration around $10 \mathrm{~g} / \mathrm{L}$ and sucrose concentration of $50 \mathrm{~g} / \mathrm{L}$ ) an increase of 10,33 and $23 \%$ respectively to yellow, orange and red colorants absorbance was achieved. These results show that $P$. purpurogenum is an alternative colorants producer and the production of these biocompounds can be improved employing statistical tool.
\end{abstract}

Key words: natural colorants; filamentous fungi; optimization; submerged culture.

\section{Introduction}

In the industries of food, cosmetic and pharmaceutical both natural and synthetic colorants are used extensively (Mapari et al., 2005; Hailei et al., 2011). But, some characteristics of synthetic colorants such as detrimental effects on environment (Shahid et al., 2013), the development of mental illness, allergies and diverse type of cancers associate with the use of artificial colorants (Ruiz-Ruiz et al., 2013) reduced the number of synthetic colorants approved by federal regulatory agencies (Santos-Ebinuma et $a l .$, 2013a). Furthermore, there is a growing demand for ecofriendly/non-toxic colorants, specifically for health sensitive applications, such as the coloration of food and dyeing of children's fabrics and leather garments (SantosEbinuma et al., 2013b). Natural colorants have been extracted from natural sources, such as plant and insect tissues (Unagul et al., 2005; Boo et al., 2012; Deveoglu et al., 2012), but also these compounds can be produced by microorganisms (Cho et al., 2002; Jiang et al., 2005; Yang et al., 2007; Méndez et al., 2011). The production by the latter is very interesting to industries because microorganisms can grow rapidly and achieve high productivity with a product available throughout the year (Jiang et al., 2005;

Send correspondence to V.C. Santos-Ebinuma. Departamento de Bioprocessos e Biotecnologia, Faculdade de Ciências Farmacêuticas, Universidade Estadual Paulista-UNESP, Araraquara, SP, Brasil. Rodovia Araraquara-Jaú/km 01, 14801-902, Araraquara, SP, Brazil; E-mail: valeriac@fcfar.unesp.br. 
Méndez et al., 2011). Furthermore, microbial colorants are often more stable and soluble than those produced by plants or animal (Gunasekaran and Poorniammal, 2008).

Many ascomycetous fungi naturally synthesize and secrete natural colorants with improved functionalities (Dubois et al., 1956; Mapari et al., 2009). The diversity of fungal colorants is not only found in their chemical structures, but also in the color range of these compounds (Mapari et al., 2009). As most of the studies found in the literature about fungal colorants were performed with Monascus species and there is a large number of other fungi to be explored, it is of interest to search for alternative colorant-producing organisms (Hailei et al., 2011).

It has recently been reported in the literature (Mapari et al., 2008; Hailei et al., 2011; Méndez et al., 2011) that Penicillium strains are potential producers of natural colorants, which have chromophore similar to Monascus colorants (Mapari et al., 2008). Among Penicillium species, $P$. purpurogenum can produce colorants not only in solid medium but also in liquid media (Méndez et al., 2011). In studies performed by our research group (Teixeira et al., 2012), P. purpurogenum DPUA 1275 showed potential to produce natural colorants with significant antimicrobial activities and total absence of toxicity against Artemia salina.

According to Meinicke et al. (2012), different factors can influence the production of secondary metabolites. So, the optimization of operating conditions such as $\mathrm{pH}$, temperature and orbital stirring speed and nutritional factors for maximum colorants production is an essential step (Mukherjee and Singh, 2011). Comparing statistical methods and classic ones for the optimization of processes, the first represent a safe and reliable alternative because they are based on the study of only one independent variable at a time, while all of the other factors are maintained at a fixed level (Gonçalves et al., 2012). Furthermore, classical approaches are intrinsically more complicated to pinpoint interactions among processing parameters (Queiroga et al., 2012).

Response surface methodology (RSM) is frequently used to optimize a process using statistic tool. The response surface methodology (RSM) model is usually constructed for the defined medium factors by quadratic polynomial equation to depict the interaction effect among the variables and is then used to optimize the bioprocess (Zafar et al., 2012). The aim of this set of statistics techniques is to execute the experimental planning by building empirical models and evaluating the effect of independent variables on the desired variable response (Box and Wilson, 1951; Gonçalves et al., 2012). It can reduce the number of experimental runs and provide sufficient information for a statistically acceptable result (Guo et al., 2012). In this way, response surface analysis and orthogonal experimental design are commonly used approaches which are useful in fermentative process optimization (Gösungur et al., 2011; Yu et al., 2012).

In this study, the influence of six independent variables (sucrose and yeast extraction concentrations, $\mathrm{pH}$, temperature, orbital stirring speed and incubation time) on the production of yellow, orange and red colorants by submerged culture of $P$. purpurogenum DPUA 1275 was evaluated employing statistical designs aiming to increase the production of natural colorants by $P$. purpurogenum.

\section{Materials and Methods}

\section{Chemicals}

Sucrose and Yeast extract were purchased respectively from Synth (São Paulo, Brazil) and Acumedia (Lansing, Michigan, USA). All the other reagents were of analytical grade and were used as received.

\section{Microorganism}

Penicillium purpurogenum DPUA 1275 was provided by the Culture Collection by Federal University of Amazon (DPUA), AM, Brazil. The stock culture was maintained on Czapeck Yeast Extract Agar (CYA) tubes. Tubes and plates were inoculated at $30^{\circ} \mathrm{C}$ for 7 days and subsequently stored at $4{ }^{\circ} \mathrm{C}$.

\section{Culture medium and inoculum preparation}

CYA medium was used as the growth medium. This medium had the following composition $(\mathrm{g} / \mathrm{L}$ in deionized water): $\mathrm{K}_{2} \mathrm{HPO}_{4}(1.0)$, yeast extract (5.0), sucrose (30.0), Agar (15.0) and $10 \mathrm{~mL} / \mathrm{L}$ of concentrated Czapeck. Concentrated Czapeck, which is a salt solution, had the following composition $\left(\mathrm{g} / 100 \mathrm{~mL}\right.$ of deionized water): $\mathrm{NaNO}_{3}$ (30.0), $\mathrm{KCl}(5.0), \mathrm{MgSO}_{4} .7 \mathrm{H}_{2} \mathrm{O}$ (5.0), $\mathrm{FeSO}_{4} .7 \mathrm{H}_{2} \mathrm{O}(0.1)$ (Pitt, 1985). The composition of the production medium was similar to the one used for the inoculum, except for the sucrose and yeast extract concentrations, which was varied according to the selected experimental design.

For production experiments, $125 \mathrm{~mL}$-Erlenmeyer flasks (Vidrolabor - ISO 1773) containing $25 \mathrm{~mL}$ of required medium were inoculated with 5 mycelial agar discs punched out with a sterilized self-designed cutter $(8 \mathrm{~mm}$ diameter) from a stock culture grown at CYA medium in Petri plates during 7 days at $30^{\circ} \mathrm{C}$. The Erlenmeyer flasks were closed using cotton plug. The $\mathrm{pH}$ values and other experimental conditions varied according to the factorial design. All experiments were performed in orbital shaker. At the end of submerged culture, which varied according factorial design, samples were collected and assayed for $\mathrm{pH}$ and yellow, orange and red colorants production.

\section{Analytical methods}

The fermented broth was filtrated (Whatman $\mathrm{N}^{\circ} 1$ filter paper, Whatman, England), and the resulting supernatant was filtered through a Millipore filter $(0.45 \mu \mathrm{m})$. The 
concentration of fungal biomass was determined by dry weight. The filtrate was used to measure the sucrose consumption, $\mathrm{pH}$ and colorants production. Sucrose concentration was determined according to Dubois et al. (1956) and the $\mathrm{pH}$ was measured using $\mathrm{pHmeter}$.

The concentration of extracellular colorants was estimated by measuring the absorbance of filtrates. Wavelength of each colorant was scanned at 350-600 $\mathrm{nm}$. The supernatant was read at 400, 470 and $490 \mathrm{~nm}$ (a wavelength which represents the absorption maxima for yellow, orange and red colorants, respectively), using the spectrophotometer model UV-1650PC (Shimadzu, Kyoto, Japan) and taking the dilution factor of each sample into consideration. The results were expressed in Units of Absorbance (UA). The absorption maxima got to each colorant is in agreement with Johns and Stuart (1991).

\section{Statistical design}

Initially, a selection of variables that influence the production of yellow, orange and red colorants by $P$. purpurogenum was carried out using three different factorial design, as follows: first a $2^{6-2}$ fractional factorial statistical design (20 experiments), second a $2^{4-1}$ fractional factorial statistical design (12 experiments) and third a $2^{3}$ full factorial design (12 experiments). After each experiment, some variables were kept constant. In this way, after the first factorial design, the temperature and fermentation time were kept at $30^{\circ} \mathrm{C}$ and $336 \mathrm{~h}$, respectively. In the second and third factorial design, the $\mathrm{pH}$ chosen was 4.5 and the orbital stirring speed, $150 \mathrm{rpm}$. The variables range and levels of the components under study to each factorial design are given in Table 1.

In the second stage, the influence of the independent variables, specifically sucrose and yeast extract concentrations, on the responses yellow, orange and red colorants production was investigated using a $2^{2}$ central composite designs. A set of 12 experiments which contained a factorial or fractional factorial matrix with center points and star points to allow estimation of the curvature (Mokhtarani et al., 2008; Viana Marques et al., 2011) was performed. The range and levels of the components under study are given in Table 2.

For statistical elaboration, the actual values of each independent variable $\left(X_{i}\right)$ were coded, to give coded levels, according to the equation:
Table 1 - Variables and factor levels used in the $2^{6-2}, 2^{4-1}$ and $2^{3}$ design for studying yellow, orange and red colorants production by $P$. purpurogenum DPUA 1275.

\begin{tabular}{lccc}
\hline Factors & \multicolumn{3}{c}{ Levels } \\
\hline & Lower $(+1)$ & Center $(0)$ & Higher $(-1)$ \\
\hline $2^{6-2}$ design & & & \\
\hline Orbital stirring speed (rpm) & 120 & 150 & 180 \\
$\mathrm{pH}$ & 4.5 & 6.0 & 7.5 \\
Temperature $\left({ }^{\circ} \mathrm{C}\right)$ & 25 & 30 & 35 \\
Sucrose $(\mathrm{g} / \mathrm{L})$ & 10 & 30 & 50 \\
Yeast extract (g/L) & 3 & 5 & 7 \\
Incubation time (h) & 144 & 240 & 336 \\
\hline $2^{4-1}$ design & & & \\
\hline Orbital stirring speed (rpm) & 120 & 150 & 180 \\
pH & 4.0 & 4.5 & 5.0 \\
Sucrose $(\mathrm{g} / \mathrm{L})$ & 50 & 60 & 70 \\
Yeast extract $(\mathrm{g} / \mathrm{L})$ & 6.0 & 7.0 & 8.0 \\
\hline $2^{3}$ design & & & \\
\hline Orbital stirring speed (rpm) & 150 & 180 & 250 \\
Sucrose $(\mathrm{g} / \mathrm{L})$ & 45 & 50 & 55 \\
Yeast extract $(\mathrm{g} / \mathrm{L})$ & 7.0 & 8.0 & 9.0 \\
\hline
\end{tabular}

$$
x_{i}=\frac{X_{i}-X_{o}}{\Delta X_{i}}
$$

where $x_{i}$ represents the corresponding coded values, $X_{o}$, the actual values at the central point, and $\Delta X_{i}$, the step change value.

To identify the best conditions for yellow, orange and red colorants production, a quadratic model expressed by the Eq. (2) was used:

$$
\hat{y}_{i}=b_{0}+\sum b_{i} x_{i}+\sum b_{i} x_{i}^{2}+\sum b_{i j} x_{i} x_{j}
$$

where $\hat{y}_{i}$ are the predicted values for each response, $b_{o}$ and $b_{i}$ the intercept and linear and quadratic coefficients, respectively, and $b_{i j}$ the interaction ones.

The "Statistica" Version 7.0 (Statsoft, Tulsa, OK, USA) software was used for regression and graphical analysis of data. The statistical significance of the regression

Table 2 - Factor levels used in the $2^{2}$ central composite design for studying yellow, orange and red colorants production by P. purpurogenum DPUA 1275 .

\begin{tabular}{lccccc}
\hline Factors & \multicolumn{5}{c}{ Levels } \\
\cline { 2 - 6 } & Axial $(-1.41)$ & Lower $(-1)$ & Center $(0)$ & Higher (1) & Axial $(+1.41)$ \\
\hline $2^{2}$ design & & & & & 60 \\
Sucrose $(\mathrm{g} / \mathrm{L})$ & 48 & 50 & 55 & 62 & 10.0 \\
Yeast Extract $(\mathrm{g} / \mathrm{L})$ & 7.6 & 8.0 & 9.0 & 10.4 \\
\hline
\end{tabular}


coefficients was determined by the Fischer's test for analysis of variance (ANOVA) at a significance level (p) $\leq 0.05$, and the extent of variance explained by each model was given by the determination coefficient $\mathrm{R}^{2}$. To minimize the error of ANOVA, the tests corresponding to the central point were repeated four times. The experimental and predicted values were compared in order to determine the validity of the models.

\section{Results and Discussion}

\section{Experimental designs to produce natural colorants}

It is known that metabolite production by microorganisms is largely influenced by the medium compounds, such as carbon and nitrogen sources, physicochemical factors, such as $\mathrm{pH}$, temperature, inoculum size, stirring intensity and incubation time (Oh et al., 2000; Celik and Calik, 2004; Mapari et al., 2005). In previous work (SantosEbinuma et al., 2013b) different carbon (glucose, fructose, sucrose, maltose and starch) and nitrogen (malt extract, ammonium sulfate, peptone, yeast extract and tryptone) sources was evaluated in order to produce natural colorants by submerged culture of $P$. purpurogenum and sucrose and yeast extract were the more suitable sources. In this way, the effect of different independent variables, specifically orbital stirring speed, $\mathrm{pH}$, temperature, incubation time and sucrose and yeast extract concentrations on the yellow, orange and red natural colorants production by $P$. purpurogenum DPUA 1275 were evaluated by using statistical tools. The experimental design methodology is very important because it allows reducing the number of experiments as well as identifying both the independent variables with statistical significance for the process and their significant interactions (Santos et al., 2011).

\section{First fractional factorial design to produce natural colorants}

Initially, a $2^{6-2}$ fractional factorial design, which is a resolution IV screening design, was performed. Its analysis is very interesting for an initial investigation, since it decreases the number of experiments, in comparison to the full factorial design with six variables. This statistical design is not completely saturated, meaning it does not mix the main effects with the first order (interaction), which secures the calculation of the variable effects in the responses studied, without losing the statistic quality of the information. This strategy is well suitable to an initial results screening, once it enables the evaluation of the main effects and, from such, deciding the strategy for the following design to obtain an optimized condition (Rodrigues and Iemma, 2005). It is natural, therefore, to assume that third-order terms are much less important than first-order ones, and, at least at a first approach, maybe neglected (Cavalcanti et al., 2006; Lima et al., 2009). In this way, the third-order interactions in the present work are negligible. The main results of natural colorants production by submerged culture of $P$. purpurogenum according to the $2^{6-2}$ fractional factorial design are shown in Table 3.

It can be observed that among the 20 runs performed, the yellow colorants production varied from 0.110 to 2.803 $\mathrm{UA}_{400 \mathrm{~nm}}$, while the orange and red ones varied from 0.016 to $1.875 \mathrm{UA}_{470 \mathrm{~nm}}$ and 0.018 to $1.660 \mathrm{UA}_{490 \mathrm{~nm}}$, respectively. However, while the highest yellow and red colorants production was obtained in run 10, it occurred in run 9 for the orange production. These runs have four variables in common: $\mathrm{pH}(4.5)$, temperature $\left(25^{\circ} \mathrm{C}\right)$, sucrose concentration $(50 \mathrm{~g} / \mathrm{L})$ and incubation time $(336 \mathrm{~h})$.

The Pareto chart to all responses is shown in Figure 1. This chart represents the estimated effects of the variables, and their interactions on the responses variables in decreasing the order of magnitude. The length of each bar is proportional to the standardized effect. The vertical line can be used to judge which effects are statistically significant. Bars extending beyond this line correspond to the statistically significant effects at a confidence level of $95 \%$ (Zea et al., 2004).

It can be seen from Figure 1A that all independent variables had a significant effect under the response yellow colorants production. However, for the orange colorants (Figure 1B), the temperature did not show a significant effect and, for the red ones, not only the temperature, but also the orbital stirring speed did not have a significant effect.

In this way, the main independent variables that showed a significant effect to all responses were incubation time, $\mathrm{pH}$ and yeast extract and sucrose concentrations. Incubation time was the main significant effect, with a positive one, which means that an increase of this parameter can improve the results. As it is known that natural colorants are, generally, secondary metabolites and a modification in the nutritional components concentration in the culture medium can promote changes not only in microorganism growth, but also in their metabolism, different incubation times were studied. However, the highest colorants production was achieved with $336 \mathrm{~h}$ of incubation time. According to previous results obtained by our research group (Santos-Ebinuma et al., 2013b) an, an incubation time higher than $336 \mathrm{~h}$ promoted a decrease on colorants production. In this way, this variable was not included in the next factorial designs and it was kept at a highest level (336 h).

Regarding $\mathrm{pH}$, the analysis indicated that low levels of this parameter can promote the highest results for colorant production. On the other hand, the variables yeast extract and sucrose concentrations showed a positive effect, and higher concentrations of both sources would improve the results. As the most part of the articles found in the literature about colorants production by Penicillium strain is using CYA medium $(30 \mathrm{~g} / \mathrm{L}$ of sucrose and $5 \mathrm{~g} / \mathrm{L}$ of yeast extract) and this is the first attempt to optimize their production using $P$. purpurogenum, there is not a concentration of both nutrients source to follow. It is known from 
Table 3 - Matrix of the $2^{6-2}$ fractional factorial design with the real variables and results of the selected responses (yellow, orange and red colorants production).

\begin{tabular}{|c|c|c|c|c|c|c|c|c|c|}
\hline Run & $\begin{array}{l}\text { Orbital stirring } \\
\text { speed (rpm) }\end{array}$ & $\mathrm{pH}$ & $\begin{array}{c}\text { Temperature } \\
\left({ }^{\circ} \mathrm{C}\right)\end{array}$ & $\begin{array}{c}\text { Sucrose } \\
(\mathrm{g} / \mathrm{L})\end{array}$ & $\begin{array}{c}\text { Yeast extract } \\
(\mathrm{g} / \mathrm{L})\end{array}$ & $\begin{array}{l}\text { Incubation time } \\
\text { (h) }\end{array}$ & $\begin{array}{c}\text { Yellow } \\
\text { Colorants } \\
\left(\mathrm{UA}_{400 \mathrm{~nm}}\right)\end{array}$ & $\begin{array}{c}\text { Orange } \\
\text { Colorants } \\
\left(\mathrm{UA}_{470 \mathrm{~nm}}\right)\end{array}$ & $\begin{array}{l}\text { Red Colorants } \\
\quad\left(\mathrm{UA}_{490 \mathrm{~nm}}\right)\end{array}$ \\
\hline 1 & 120 & 4.5 & 25 & 10 & 3 & 144 & 0.11 & 0.02 & 0.02 \\
\hline 2 & 180 & 4.5 & 25 & 10 & 7 & 144 & 0.60 & 0.24 & 0.16 \\
\hline 3 & 120 & 7.5 & 25 & 10 & 7 & 336 & 0.75 & 0.30 & 0.19 \\
\hline 4 & 180 & 7.5 & 25 & 10 & 3 & 336 & 0.59 & 0.22 & 0.14 \\
\hline 5 & 120 & 4.5 & 37 & 10 & 7 & 336 & 2.61 & 1.73 & 1.00 \\
\hline 6 & 180 & 4.5 & 37 & 10 & 3 & 336 & 0.85 & 0.45 & 0.34 \\
\hline 7 & 120 & 7.5 & 37 & 10 & 3 & 144 & 0.66 & 0.28 & 0.22 \\
\hline 8 & 180 & 7.5 & 37 & 10 & 7 & 144 & 0.72 & 0.38 & 0.28 \\
\hline 9 & 120 & 4.5 & 25 & 50 & 3 & 336 & 2.62 & 1.88 & 1.17 \\
\hline 10 & 180 & 4.5 & 25 & 50 & 7 & 336 & 2.80 & 1.33 & 1.66 \\
\hline 11 & 120 & 7.5 & 25 & 50 & 7 & 144 & 0.71 & 0.04 & 0.02 \\
\hline 12 & 180 & 7.5 & 25 & 50 & 3 & 144 & 0.30 & 0.10 & 0.07 \\
\hline 13 & 120 & 4.5 & 37 & 50 & 7 & 144 & 0.91 & 0.29 & 0.18 \\
\hline 14 & 180 & 4.5 & 37 & 50 & 3 & 144 & 0.37 & 0.14 & 0.09 \\
\hline 15 & 120 & 7.5 & 37 & 50 & 3 & 336 & 1.45 & 0.40 & 0.25 \\
\hline 16 & 180 & 7.5 & 37 & 50 & 7 & 336 & 2.24 & 1.07 & 0.98 \\
\hline $17(\mathrm{C})$ & 150 & 6.0 & 30 & 30 & 5 & 240 & 1.25 & 0.66 & 0.45 \\
\hline $18(\mathrm{C})$ & 150 & 6.0 & 30 & 30 & 5 & 240 & 1.12 & 0.78 & 0.56 \\
\hline $19(\mathrm{C})$ & 150 & 6.0 & 30 & 30 & 5 & 240 & 1.24 & 0.80 & 0.58 \\
\hline $20(\mathrm{C})$ & 150 & 6.0 & 30 & 30 & 5 & 240 & 1.11 & 0.67 & 0.59 \\
\hline
\end{tabular}

C - Central points.

the literature that it is required not only to supplement the culture medium but also to control the components in order to achieve an efficient and fast conversion of carbon source in the desired product with the highest possible productivity. Furthermore, once the nutritional needs are supplied, most of the fungi grow under $\mathrm{pH}$ values from 4.0 to 7.0 (Carlile and Watkinson, 1996).

The orbital stirring speed [1] showed a significant effect when interacting with $\mathrm{pH}[1 * 5]$, sucrose [1*2] and yeast extract $[1 * 4]$. The interaction between $\mathrm{pH}$ and incubation time $[2 * 6]$ also showed a significant effect under all responses. The interaction $1 * 5$ was significant in the highest level [+]. As independent variable, the yeast extract concentration was significant in the highest level. Thus, to keep the interactions with this nitrogen source in the highest level, the orbital stirring speed has to be kept in the same level. For interaction $1 * 4$, the same argument used for interaction $1 * 5$ can be applied, and the orbital stirring speed level has to be used in the highest level. For interaction $1 * 2$, the factorial design showed that working with interactions in the highest level is more favorable. As for variable $\mathrm{pH}$, the factorial design showed that the lowest level was better to obtain the highest level among the interactions, and the orbital stirring speed has to be used in the highest level.

As the temperature was significant only for yellow colorants, in the next factorial design this variable will be kept at $30^{\circ} \mathrm{C}$, which was the central point used in this factorial design. It is known that many fungi usually require long periods to grow by submerged culture, and are exposed to contamination risk; this temperature is considered favorable to keep the physiological properties of the microorganisms (Gunasekaran and Poorniammal, 2008).

To all answers evaluated the error pure was lower than 0.006 and the determination coefficient for the yellow, orange and red colorants was 96.51, 91.64 and 97.34. According to Silva et al. (2009) values of $\mathrm{R}^{2}>90 \%$ are very good in the experimental design of bioprocesses.

Even though the orbital stirring speed as main variable did not have a significant effect on all responses, its interaction with many independent variables was significant. This fact is probably related to microorganism metabolism. As the microorganism used in this work is a filamentous fungus, it can grown in the form of a pellet, increasing the medium viscosity and promoting problems in mass trans- 
fer, which results in lower productivity. It is known from the literature that for each culture, the optimum conditions of stirring intensity will partially depend on hyphae resistance to mechanic force and to its physiologic study, as well (Papagianni, 2004). Thus, finding the best orbital stirring speed is essential for improving the production and this

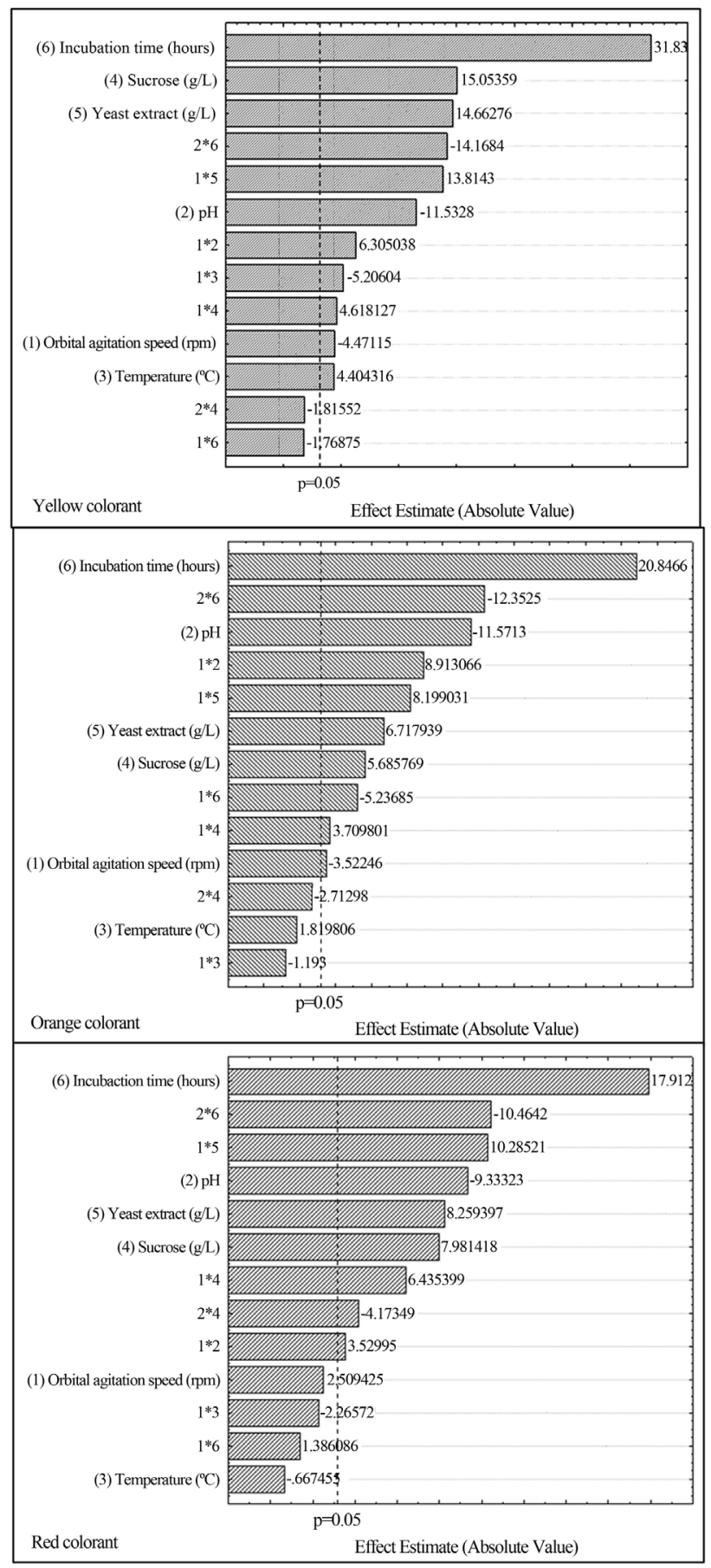

Figure 1 - Pareto chart for the effects of variables orbital stirring speed (1), $\mathrm{pH}(2)$, temperature (3), sucrose (4), yeast extract (5) and incubation time (6) on yellow (A), orange (B) and red (C) natural colorants production according to a $2^{6-2}$ fractional factorial design. variable was included in the next factorial design in the same range previously studied.

Figure 2 shows the results about biomass, sucrose consumption and $\mathrm{pH}$ in each run carried out according to a $2^{6-2}$ fractional factorial design.

It was expected that the runs $1,2,7$ and 8 , which ended up with $240 \mathrm{~h}$ of incubation time, showed higher biomass concentration as compared with the other runs because this time is located in the exponential phase of cell growth (Santos-Ebinuma et al., 2013b); however, these results were not achieved. This behavior probably occurred due the low sucrose concentration $(10 \mathrm{~g} / \mathrm{L})$ in these runs. Comparing these results with the ones obtained in the runs with initial sucrose concentration of $50 \mathrm{~g} / \mathrm{L}$ at the same incubation time the hypothesis cited before can be confirmed since the biomass concentration obtained in this condition was higher than the others. According to Santos-Ebinuma et al. (2013b), the orange and red colorants production increases after $168 \mathrm{~h}$ of incubation, which means that these metabolites have characteristics to be secondary ones, since their formation started to be more significant in the moment that the main carbon source had been almost completely consumed and the microorganism was in the decline phase.

Regarding sucrose consumption, the runs $3,4,5$ and 6 promoted the maximum consumption of sucrose leading the lowest final sucrose concentration. In these runs, the initial sucrose concentration was $10 \mathrm{~g} / \mathrm{L}$, which can be the responsible for the microorganism sucrose consumption until exhaustion. In the other runs, the sucrose consumption occurred as expected.

Based on the analyzed results, four variables - yeast extract and sucrose concentrations, $\mathrm{pH}$ and orbital stirring speed - were selected to be evaluated by a $2^{4-1}$ fractional factorial design. The other variables were fixed at 336-h incubation period and $30^{\circ} \mathrm{C}$ of temperature.

\section{Second Fractional Factorial design to produce natural colorants}

The fractional factorial design $2^{4-1}$ is an useful method to evaluate the impact of the variables under the responses and to define the conditions of the following facto-

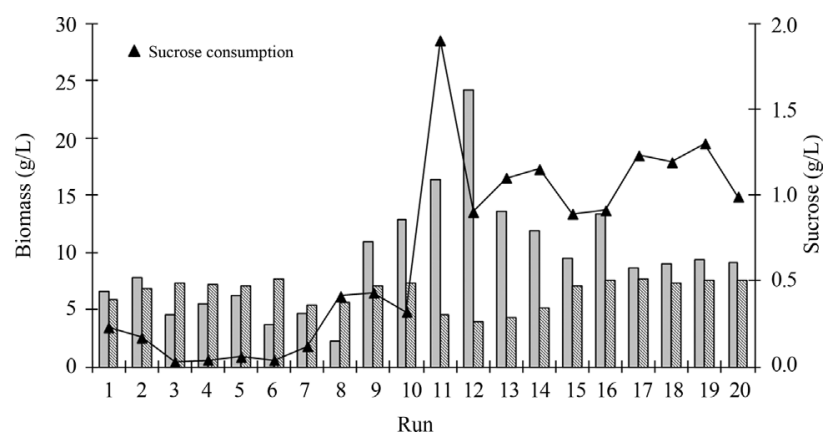

Figure 2 - Biomass (gray bars), sucrose consumption and $\mathrm{pH}$ (striped bars) in the runs performed according to a $2^{6-2}$ fractional factorial design. 
Table 4 - Analysis of variance applied to the regression models used for yellow colorants production as function of $\mathrm{pH}$, orbital stirring speed and sucrose and yeast extract concentrations, according to $2^{4-1}$ fractional factorial design.

\begin{tabular}{|c|c|c|c|}
\hline Source & $\mathrm{p}$ value Yellow Colorants & $\mathrm{p}$ value Orange Colorants & $\mathrm{p}$ value Red Colorants \\
\hline (1) $\mathrm{pH}$ & 0.071514 & 0.634352 & 0.093393 \\
\hline (2) Orbital stirring speed (rpm) & $0.005608^{*}$ & 0.093774 & $0.002189 *$ \\
\hline (3) Yeast extract (g/L) & $0.000104 *$ & $0.007302 *$ & $0.000024 *$ \\
\hline (4) Sucrose (g/L) & $0.000004 *$ & $0.000978 *$ & $0.000361 *$ \\
\hline $1 * 2$ & $0.001015^{*}$ & $0.002324 *$ & $0.008177 *$ \\
\hline $1 * 3$ & $0.006540^{*}$ & 0.089051 & $0.000196^{*}$ \\
\hline $1 * 4$ & $0.000346^{*}$ & 0.134367 & 0.201925 \\
\hline
\end{tabular}

*significant level $\mathrm{p}<0.05 ; \mathrm{R}^{2}=97 \% . \mathrm{R}^{2}=92 \%$ (orange colorants). $\mathrm{R}^{2}=93 \%$ (red colorants).

rial design. Table 4 shows the p-value to responses yellow, orange and red colorants.

The statistical analysis of the results showed that, in the range studied, the yellow, orange and red colorants production was significantly affected by the yeast extract and sucrose concentrations. Moreover, the interaction between $\mathrm{pH}$ and orbital stirring speed [ $1 * 2]$ also showed a significant effect on all responses. The orbital stirring speed and the interactions between $\mathrm{pH}$ and yeast extract also had a significant effect on yellow and red colorants. In addition, the interaction between $\mathrm{pH}$ and sucrose was significant to the yellow colorants production.

The fit of the model was checked by the coefficient of determination $\mathrm{R}^{2}$, which was calculated as $0.97,0.92$ and 0.93 to yellow, orange and red colorants, respectively. It indicates that 97,92 and $93 \%$ of the variability could be explained by the model for the respective response. The analysis of variance (ANOVA) for the yellow, orange and red colorants are presented in the Supporting Information (Table A.1, A.2 and A.3, respectively).

The effect of the interaction between the variables $\mathrm{pH}$ and orbital stirring speed was negative. In this way, a variable should be in the lowest level while the other is in its higher level to promote the best results. So, when the $\mathrm{pH}$ was in its lower level (4.0) and the orbital stirring speed was in its higher level (180 rpm), the highest effect was observed.

The highest production was obtained in the highest yeast extract concentration, regardless of $\mathrm{pH}$ and orbital stirring speed. In this study, it was observed that the $\mathrm{pH}$, despite being significant in the interactions, can be considered inert, which means that it did not have any effect in the responses variables. In this way, this variable was fixed at 4.5 in the next designs, which represents the central point in this study.

The yeast extract and sucrose concentrations were essentially significant to the responses, at a positive level, which means that an increase in their concentrations can improve the results. High yeast extract concentration promoted an increase in the extracellular colorants production, probably due to its reaction with groups containing amine component in the medium to form water soluble complexes (Pastrana et al., 1995). The biomass concentration, sucrose consumption and $\mathrm{pH}$ for all runs every $48 \mathrm{~h}$ are presented in the Supporting Information (see Figure A.1).

Not only sucrose concentration, but also yeast extract was kept to be evaluated in a future factorial design. As the orbital stirring speed was significant to two responses (yellow and red colorants production), this independent variable was also studied in a new factorial design.

\section{Full Factorial design to produce natural colorants}

After a selection of the variables that significantly influenced the natural colorants production by $P$. purpurogenum DPUA using fractional design, the independent variables orbital stirring speed, yeast extract and sucrose concentrations were evaluated for their effects under the yellow, orange and red natural colorants through a $2^{3}$ full factorial design. Figure 3 shows the Pareto chart under the response variable yellow colorants.

Regarding the independent variables, sucrose and yeast extract concentrations had a significant effect on all responses. Considering the interactions, the ones among the orbital stirring speed and both sucrose and yeast extract concentrations showed significant effect. All significant effects showed a positive one, except the interaction between orbital stirring speed and yeast extract. As the highest yeast extract concentration promoted a high production of colorants, the orbital stirring speed has to be used in the lowest level and in the next factorial design this variable will be fixed in the central point $(150 \mathrm{rpm})$, which can promote a good homogenization of the medium to avoid problems in the mass transfer during the fermentation process.

Analyzing all results obtained for the studied responses, a higher influence of yeast extract and sucrose concentrations under the natural colorants production, both in the highest level, can be observed. This result shows that the studied concentrations have not yet exert an effect of catabolic repression in microorganism metabolism. In this way, both variables were analyzed using a central compos- 


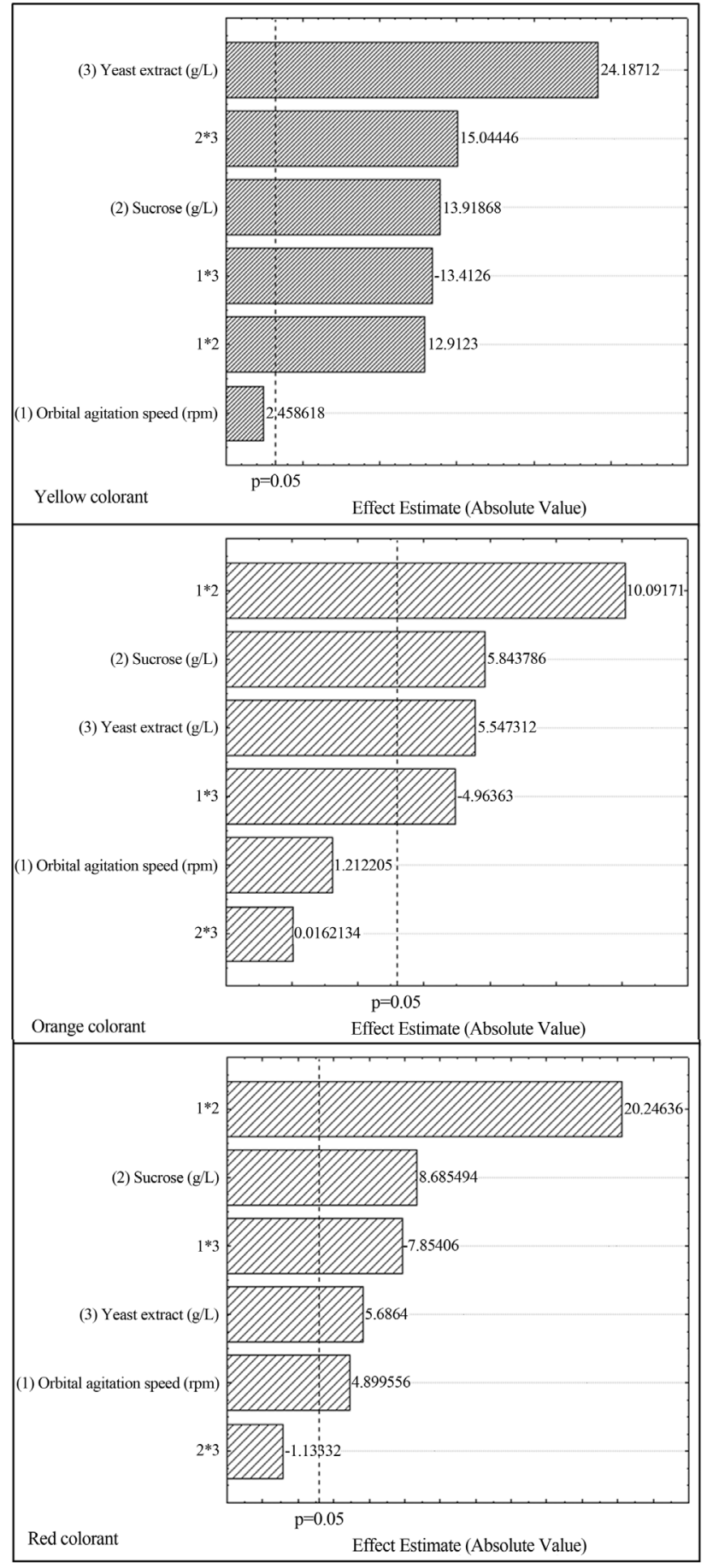

Figure 3 - Pareto chart for the effects of variables orbital stirring speed (1), $\mathrm{pH}(2)$, temperature (3), sucrose (4), yeast extract (5) and incubation time (6) on yellow (A), orange (B) and red (C) natural colorants production according to a $2^{3}$ full factorial design.

ite design. The biomass concentration, sucrose consumption and $\mathrm{pH}$ for all runs every $48 \mathrm{~h}$ are presented in the Supporting Information (see Figure A.2).

\section{Central composite factorial design to produce natural colorants}

From the factorial designs showed above, sucrose and yeast extract concentrations were the most significant variables in the production of natural colorants by $P$. purpurogenum DPUA 1275. These variables were, therefore, analyzed by a central composite factorial design with 4 replications in the central point, with the purpose of optimizing the production of these metabolites. The results from these runs are showed at Table 5 .

From Table 5, it can be observed that the yellow colorants production varied from 1.79 to $3.14 \mathrm{UA}_{400 \mathrm{~nm}}$, the orange colorants varied from 1.20 to $2.50 \mathrm{UA}_{470 \mathrm{~nm}}$ and the red colorants, from 1.10 to $2.04 \mathrm{UA}_{490 \mathrm{~nm}}$. For the yellow colorants, the highest result was obtained in run 8 , in which the yeast extract and sucrose concentrations were 10.4 and $55 \mathrm{~g} / \mathrm{L}$, respectively. For the orange and red colorants, the highest production occurred in run $2(50 \mathrm{~g} / \mathrm{L}$ of sucrose and $10 \mathrm{~g} / \mathrm{L}$ of yeast extract concentrations). The results obtained in this factorial design are higher than the ones obtained in the factorial designs above, which shows the conduction of a factorial design to an increase in the production of natural colorants. The central composite factorial design for the yellow, orange and red colorants did not show lack of fit (see Table A.4, Table A.5 and Table A.6 from Supporting Information).

Figure 4 shows the response surface indicating the simultaneous effects of the independent variables under the response variables yellow, orange and red colorants. It can be observed that, to all responses studies, there is a possibility to improve the colorants production by varying the conditions of the fermentative process. The surface response indicates that the best results would be possible if higher concentrations of yeast extract were used. Table 6 shows the probability values $(\mathrm{p})$ for the yellow, orange and red colorants. From the $p$ value, it is possible to determine which variables were significant to the process. Since in this work a confidence level of $95 \%$ was considered, the independent variables with $\mathrm{p}$ values lower than 0.05 are considered significant.

Through the results of the statistical analysis for the responses yellow, orange and red colorants, it was observed that the yeast extract in the linear and quadratic terms had a significant effect. Furthermore, the interaction between the linear terms of the variables also showed significant effects to the responses orange and red colorants. The biomass concentration, sucrose consumption and $\mathrm{pH}$ for all runs every $48 \mathrm{~h}$ are presented in the Supporting Information (see Figure A.3).

On the basis of the results of the complete regressions, the following models were determined to sucrose $\left(\mathrm{x}_{1}\right)$ and yeast extract $\left(\mathrm{x}_{2}\right)$ under the production of yellow $\left(\mathrm{y}_{1}\right)$, orange $\left(\mathrm{y}_{2}\right)$ and red $\left(\mathrm{y}_{3}\right)$ colorants, as described by the following equations:

$$
y_{1}=2.10-0.05 x_{1}-0.04 x_{1}^{2}+0.31 x_{2}+0.32 x_{2}^{2}-
$$

$0.28 x_{1} x_{2}$ 

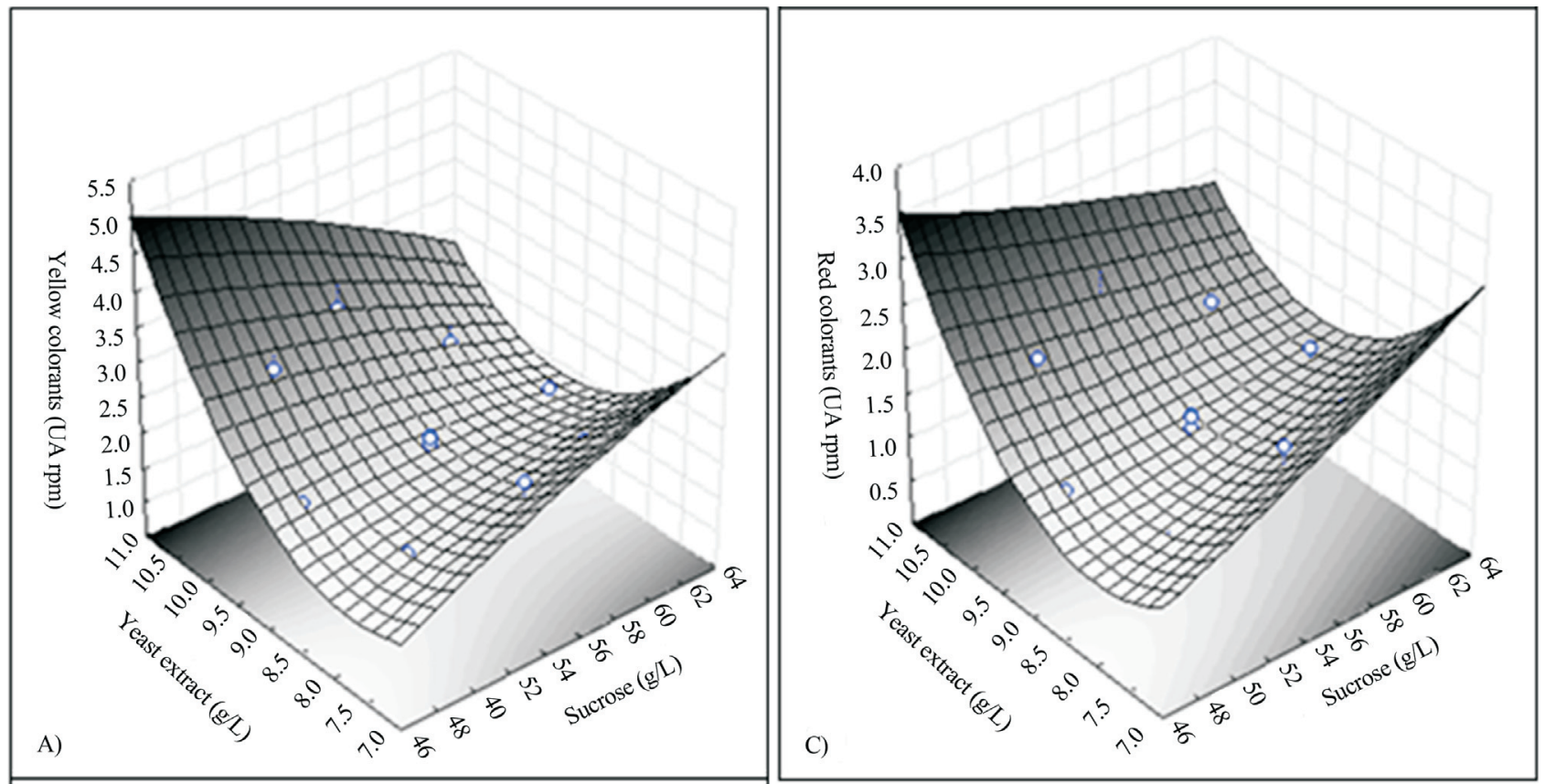

B)

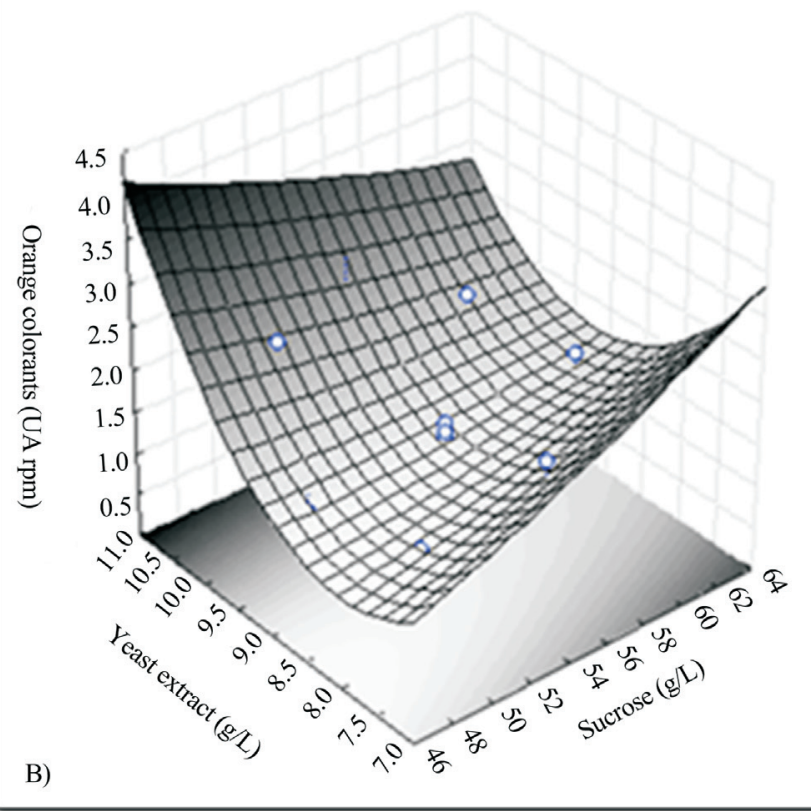

Figure 4 - Response surface showing the simultaneous effects of sucrose and yeast extract concentrations on the yellow (A), orange (B) and red (C) colorants by submerged culture of $P$. purpurogenum DPUA 1275 .

$$
\begin{aligned}
& -0.23 x_{1} x_{2} \\
& y_{3}=1.33+0.09 x_{1}+0.02 x_{1}^{2}+0.20 x_{2}+0.28 x_{2}^{2} \\
& -0.20 x_{1} x_{2}
\end{aligned}
$$$$
y_{2}=1.44+0.07 x_{1}+0.03 x_{1}^{2}+0.27 x_{2}+0.35 x_{2}^{2}
$$

So, according to convenience different conditions can be profitably exploited to maximize the production of yellow, orange and red colorants. However, the run $2(50 \mathrm{~g} / \mathrm{L}$ of sucrose and $10 \mathrm{~g} / \mathrm{L}$ of yeast extract) can be selected as the best ones for the colorants production, being able to ensure, at the same time, satisfactory results of yellow, orange and red colorants production. A comparison between the best results presented in the in the first experimental design ( $\mathrm{Ta}-$ ble 3 ) and the ones achieved in the run 2 shows that an increase of 10,33 and $23 \%$ was achieved to yellow, orange and red colorants, respectively.

According the results obtained through all designs, it is very important the control of the sucrose and yeast extract concentrations during the colorants process by $P$. purpurogenum, an alternative colorant producer. Moreover, from the economic/industrial point of view, the use of a cheap carbon source such as sucrose is interesting. Fur- 
Table 5 - Matrix of $2^{2}$ central composite factorial design to responses yellow $\left(\mathrm{UA}_{400 \mathrm{~nm}}\right)$, orange $\left(\mathrm{UA}_{470 \mathrm{~nm}}\right)$ and red colorants $\left(\mathrm{UA}_{490 \mathrm{~nm}}\right)$.

\begin{tabular}{|c|c|c|c|c|c|}
\hline Run & Sucrose $(g / L)$ & $\begin{array}{c}\text { Yeast Extract } \\
(\mathrm{g} / \mathrm{L})\end{array}$ & Yellow Colorants $\left(\mathrm{UA}_{400 \mathrm{~nm}}\right)$ & Orange Colorants $\left(\mathrm{UA}_{470 \mathrm{~nm}}\right)$ & Red Colorants $\left(\mathrm{UA}_{490 \mathrm{~nm}}\right)$ \\
\hline 1 & 50 & 8 & 1.79 & 1.20 & 1.01 \\
\hline 2 & 50 & 10 & 3.10 & 2.50 & 2.04 \\
\hline 3 & 60 & 8 & 2.16 & 1.67 & 1.57 \\
\hline 4 & 60 & 10 & 2.34 & 2.04 & 1.79 \\
\hline 5 & 48 & 9 & 2.07 & 1.27 & 1.26 \\
\hline 6 & 62 & 9 & 2.05 & 1.68 & 1.56 \\
\hline 7 & 55 & 7.6 & 2.42 & 1.92 & 1.80 \\
\hline 8 & 55 & 10.4 & 3.14 & 2.25 & 2.03 \\
\hline $9(\mathrm{C})$ & 55 & 9 & 2.20 & 1.35 & 1.17 \\
\hline $10(\mathrm{C})$ & 55 & 9 & 1.97 & 1.57 & 1.44 \\
\hline $11(\mathrm{C})$ & 55 & 9 & 2.07 & 1.38 & 1.30 \\
\hline $12(\mathrm{C})$ & 55 & 9 & 2.15 & 1.47 & 1.42 \\
\hline
\end{tabular}

C - Central points.

Table 6 - p-values to the independent variables sucrose and yeast extract in the production of yellow, orange and red colorants by submerged culture of $P$. purpurogenum DPUA 1275.

\begin{tabular}{lccc}
\hline Source & p value Yellow Colorants & p value Orange Colorants & p value Red Colorants \\
\hline$(1)$ Sucrose $(g / L)(L)$ & 0.243554 & 0.133879 & 0.129119 \\
Sucrose $(g / L)(Q)$ & 0.374487 & 0.486239 & 0.698317 \\
$(2)$ Yeast extract (g/L) (L) & $0.002839^{*}$ & $0.005012^{*}$ & $0.021401^{*}$ \\
Yeast extract (g/L) (Q) & $0.003586^{*}$ & $0.003417^{*}$ & $0.011214^{*}$ \\
$1 \mathrm{~L}^{*} 2 \mathrm{~L}$ & 0.010056 & $0.019799^{*}$ & $0.047279^{*}$ \\
\hline
\end{tabular}

*significant level $\mathrm{p}<0.05 ; \mathrm{L}=$ Linear terms; $\mathrm{Q}=$ Quadratic terms.

ther investigation to improve the colorants production in a bench-scale fermenter is a future effort aiming the scale-up for an industrial application.

\section{Conclusions}

The results obtained from the factorial designs, which analyzed the independent variables incubation period, orbital stirring speed, $\mathrm{pH}$, temperature, sucrose and yeast extract concentrations under the production of yellow, orange and red colorants, suggested that sucrose and yeast extract concentrations are the most significant variables to the process of obtaining natural colorants by submerged culture of P. purpurogenum DPUA 1275, and the ideal concentrations of these subtract are values close to 50 and $10 \mathrm{~g} / \mathrm{L}$, respectively. Furthermore, the new strain showed potential to be used as a new source of natural colorants.

\section{Acknowledgments}

Financial support is gratefully acknowledged from FAPESP (Fundação de Amparo à Pesquisa do Estado de São Paulo, São Paulo, Brazil) in the form of scholarships to V.C. Santos-Ebinuma, from CNPq (National Council for Scientific and Technological Development, Brasília, Brazil) and CAPES (Coordenação de Aperfeiçoamento de Pessoal de Nível Superior).

\section{References}

Boo HO, Hwang SJ, Bae CS, Park SH, Heo BG, Gorinstein S (2012) Extraction and characterization of some natural plant pigments Ind Crop Prod 40:129-135.

Box GEP, Wilson KB (1951) On the experimental attainment of optimum conditions J R Stat Soc Ser B, 13: 1-45.

Carlile JM, Watkinson SC (1996) Genetic variation and evolution The fungi United Kingdom, Academic Press.

Cavalcanti MTH, Porto TS, Barros Neto B, Lima-Filho JL, Porto ALF, Pessoa Jr A (2006) Aqueous two-phase systems ex- 
traction of toxin from Clostridium perfringers type A. J Chromatogr 833:135-140.

Celik E, Calik P (2004) Bioprocess parameters and oxygen transfer characteristics in beta-lactamase production by Bacillus species. Biotechnol Progr 20:491-499.

Cho YJ, Park JP, Hwang HJ, Kim SW, Choi JW, Yun J W (2002) Production of red pigment by submerged culture of Paecilomyces sinclairii. Lett Appl Microbiol 35:195-202.

Deveoglu O, Cakmakcy E, Taskopru T, Torgan E, Karadag R (2012) Identification by RP-HPLC-DAD FTIR TGA and FESEM-EDAX of natural pigments prepared from Datisca cannabina L Dyes Pigments 94:437-442.

Dubois M, Gilles KA, Hamilton JK, Rebers PA, Smith F (1956) Colorimetric Method for determination of sugars and relate compounds. Anal Chem 28:350-356.

Duran N, Teixeira MFS, de Conti R, Esposito E (2002) Ecological-friendly pigments from fungi. Crit Rev Food Sci Nutr 42:53-66

Gonçalves DB, Teixeira JA, Bazzolli DMS, Queiroz MV, Araújo EF (2012) Use of response surface methodology to optimize production of pectinases by recombinant Penicillium griseoroseum T20. Biocatal Agric Biotechnol 1:140-146.

Gösungur Y, Uzunogullarí P, Dagbaglí S (2011) Optimization of pullulan production from hydrolysed potato starch waste by response surface methodology. Carbohyd Polym 83:1330-1337.

Gunasekaran S, Poorniammal R (2008) Optimization of fermentation conditions for red pigment production from Penicillium sp under submerged cultivation. Afr J Biot 7:1894-1898.

Guo J, Zhuang Y, Chen L, Liu J, Li D,Ye N (2012) Process optimization for microwave-assisted direct liquefaction of Sargassum polycystum CAgardh using response surface methodology. Bioresource Technol 120:19-25.

Hailei W, Zhifang R, Ping L, Yanchang G, Guosheng L, Jianming $Y$ (2011) Improvement of the production of a red pigment in Penicillium sp HSD07B synthesized during co-culture with Candida tropicalis. Bioresource Technol 102:6082-6087.

Jiang Y, Li HB, Chen F, Hyde KD (2005) Production potential of water-soluble Monascus red pigment by a newly isolated Penicillium sp. J Agric Technol 1:113-126.

Johns MR, Stuart DM (1991) Production of pigments by Monascus purpureus in solid culture. J Ind Microbiol 8:23-38

Kongruang S (2011) Growth kinetics of biopigment production by Thai isolated Monascus purpureus in a stirred tank bioreactor. J Ind Microbiol Biot 38:93-99.

Lima AC, Rodrigues PMB, Porto TS, Viana DA, Lima-Filho JL, Porto ALF, Cunha MGC (2009) Production of a collagenase from Candida albicans URM3622. Biochem Eng J 43:315320.

Mapari SAS, Nielsen KF, Larsen TO, Frisvad JC, Meyer AS, Thrane U (2005) Exploring fungal biodiversity for the production of water-soluble pigments as potential natural food colorants. Curr Opin Biotechnol 16:231-238.

Mapari SAS, Hansen ME, Meyer AS, Thrane U (2008) Computerized screening for novel producers of Monascus-like food pigments in Penicillium species. J Agric Food Chem 56:9981-9989.

Mapari SAS, Meyer AS, Thrane U, Frisvad JC (2009) Identification of potentially safe promising fungal cell factories for the production of polyketide natural food colorants using chemotaxonomic rationale. Microb Cell Fact 8:24.

Meinicke RM, Vendruscolo F, Moritz DE, de Oliveira D, Schmidell W, Samohyl RW, Ninow JL (2012) Potential use of glycerol as substrate for the production of red pigments by Monascus ruber in submerged fermentation. Biocatal Agri Biotechnol 1:238-242.

Méndez A, Pérez C, Montañéz JC, Martínez G, Aguilar CN (2011) Red pigment production by Penicillium purpurogenum $\mathrm{GH} 2$ is influenced by $\mathrm{pH}$ and temperature. Journal of Zhejiang Univ-SCI B (Biomed \& Biotechnol) 12:961-968.

Mokhtarani B, Karimzadeh R, Amini MH, SManesh D (2008) Partitioning of Ciprofloxacin in aqueous two-phase system of poly(-ethylene glycol) and sodium sulphate. Biochem Eng J 38:241-247.

Mukherjee G, Singh SK (2011) Purification and characterization of a new red pigment from Monascus purpureus in submerged fermentation. Process Biochem 46:188-192.

Oh YS, Shih IL, Tzeng YM, Wang SL (2000) Protease produced by Pseudomonas aeruginosa K-187 and its application in the deproteinization of shrimp and crab Shell wastes. Enzyme Microb Tech 27:3-10.

Papagianni M (2004) Fungal morphology and metabolite production in submerged mycelial processes. Biotechnol Adv $22: 189-259$

Pastrana L, Blanc PJ, Santerre AL, Loret M, Goma G (1995) Production of Red Pigments by Monascus mber in Synthetic Media with a Strictly Controlled Nitrogen Source. Process Biochem 30:333-341.

Pitt J (1985) A laboratory guide to Common Penicillium species CSIRO Australia.

Queiroga AC, Pintado ME, Malcata FX (2012) Use of response surface methodoly to optimize protease synthesis by a novel strain of Bacillus sp Isolated from Portuguese sheep wool. J Appl Microbiol 113:36-43.

Rodrigues MI, Iemma AF (2005) Planejamento de Experimentos e Otimização de Processos Uma estratégia sequencial de planejamentos. Casa do Pão Editora, Campinas.

Santos-Ebinuma VC, Roberto IC, Teixeira MFS, Pessoa Jr A (2013a) Improving of Red Colorants Production by a New Penicillium purpurogenum Strain in Submerged Culture and the Effect of Different Parameters in Their Stability. Biotechnol Prog 29:778-785.

Santos-Ebinuma VC, Teixeira MFS, Pessoa Jr A (2013b) Submerged culture conditions for the production of alternative natural colorants by a newly isolated Penicillium purpurogenum DPUA 1275. J Microbiol Biotechn $23: 802-810$

Santos VC, Hasmann FA, Converti A, Pessoa Jr A (2011) Liquid-liquid extraction by mixed micellar systems: A new approach for clavulanic acid recovery from fermented broth. Bioch Eng J 56:75-83.

Silva CS, Bovarotti E, Rodrigues M I, Hokka C O, Barboza M (2009) Evaluation of the effects of the parameters involved in the purification of clavulanic acid from fermentation broth by aqueous two-phase systems. Bioprocess Biosyst Eng 29:325-632.

Teixeira MFS, Martins MS, Da Silva J, Kirsch LS, Fernandes OCC, Carneiro ALB, De Conti R, Durán N (2012) Amazonian Biodiversity: Pigments from Aspergillus and 
Penicillium-Characterizations antibacterial activities and their toxicities. Curr Trends Biotechnol Pharm 6:300-311.

Unagul P, Wongsa P, Kittakoop P, Intamas S, Srikitikulchai P (2005) Production of red pigments by the insect pathogenic fungus Cordyceps unilateralis BCC 1869. J Ind Microbiol Biot 32:135-140.

Viana Marques DA, Pessoa Junior A, Lima-Filho JL, Converti A, Perego P, Porto ALF (2011) Extractive Fermentation of Clavulanic Acid by Streptomyces DAUFPE 3060 Using Aqueous Two-Phase System. Biotechnol Prog 27:95-103.

Yang LH, Xiong H, Lee OO, Qi SH, Qian PY (2007) Effect of agitation on violacein production in Pseudoalteromonas luteoviolacea isolated from a marine sponge. Lett Appl Microbiol 44:625-630.

Yu X, Wang Y, Wei G, Dong Y (2012) Media optimization for elevated molecular weight and mass production of pigment free pullulan. Carbohyd Polym 89:928-934.

Zafar M, Kumar S, Dhiman AK (2012) Optimization of polyhydroxybutyrate (PHB) production by Azohydromonas lata MTCC 2311 by using genetic algorithm based on artificial neural network and response surface methodology. Biocatal Agric Biotechnol 1:70-79.

Zea DVL, Mayerhoff A, Roberto IC, Franco TT (2004) Purification of xylose reduxtase from Candida mogii in aqueous two-phase systems. Bioch Eng J 18:217-223.

All the content of the journal, except where otherwise noted, is licensed under a Creative Commons License CC BY-NC. 